\title{
Estimates of Serotonin and Norepinephrine Transporter Inhibition in Depressed Patients Treated with Paroxetine or Venlafaxine
}

\author{
Michael J Owens",', Stan Krulewicz ${ }^{2}$, Jeffrey S. Simon ${ }^{3}$, David V Sheehan ${ }^{4}$, Michael E Thase ${ }^{5}$, \\ David J Carpenter ${ }^{2}$, Susan J Plott' and Charles B Nemeroff' \\ 'Laboratory of Neuropsychopharmacology, Department of Psychiatry and Behavioral Sciences, Emory University School of Medicine, Atlanta, GA, \\ USA; ${ }^{2}$ Clinical Psychiatry North America, Neurosciences Medicines Development Center, GlaxoSmithKline, King of Prussia, PA, USA; ${ }^{3}$ Northbrooke \\ Research Center, Brown Deer, WI, USA; ${ }^{4}$ Department of Psychiatry, University of South Florida, Tampa, FL, USA; ${ }^{5}$ Department of Psychiatry, \\ University of Pennsylvania, Philadelphia Veterans Affairs Medical Center, Philadelphia, PA, USA
}

\begin{abstract}
Paroxetine and venlafaxine are potent serotonin transporter (SERT) antagonists and weaker norepinephrine transporter (NET) antagonists. However, the relative magnitude of effect at each of these sites during treatment is unknown. Using a novel blood assay that estimates CNS transporter occupancy we estimated the relative SERT and NET occupancy of paroxetine and venlafaxine in human subjects to assess the relative magnitude of SERT and NET inhibition. Outpatient subjects $(N=86)$ meeting criteria for major depression were enrolled in a multicenter, 8 week, randomized, double-blind, parallel group, antidepressant treatment study. Subjects were treated by forced-titration of paroxetine CR ( $12.5-75 \mathrm{mg} /$ day) or venlafaxine XR (75-375 mg/day) over 8 weeks. Blood samples were collected weekly to estimate transporter inhibition. Both medications produced dose-dependent inhibition of the SERT and NET. Maximal SERT inhibition at week 8 for paroxetine and venlafaxine was 90\% (SD 7) and 85\% (SD 10), respectively. Maximal NET inhibition for paroxetine and venlafaxine at week 8 was 36\% (SD 19) and 60\% (SD 13), respectively. The adjusted mean change from baseline (mean 28.6) at week 8 LOCF in MADRS total score was - 16.7 (SE 8.59) and - 17.3 (SE 8.99) for the paroxetine and venlafaxine-treated patients, respectively. The magnitudes of the antidepressant effects were not significantly different from each other $(95 \% \mathrm{Cl}-3.42,4.54$, $p=0.784$ ). The results clearly demonstrate that paroxetine and venlafaxine are potent SERT antagonists and less potent NET antagonists in vivo. NET antagonism has been posited to contribute to the antidepressant effects of these compounds. The clinical significance of the magnitude of NET antagonism by both medications remains unclear at present.

Neuropsychopharmacology (2008) 33, 320I-32I2; doi: I0.1038/npp.2008.47; published online 16 April 2008
\end{abstract}

Keywords: antidepressant; transporters; reuptake; occupancy; depression; SSRI

\section{INTRODUCTION}

The majority of antidepressants used to treat major depressive disorder (MDD) are primarily antagonists at the human serotonin (SERT) and/or norepinephrine transporters (NET) (Owens et al, 1997, 2001; Nemeroff and Owens, 2002). The percentage of patients exhibiting response and remission to either selective norepinephrine uptake inhibitors or SSRIs in an acute, randomized, double-blind clinical trial is approximately $60 \%$ and $35-40 \%$, respectively (Lieberman et al, 2005; Nemeroff and Schatzberg, 2006).

\footnotetext{
*Correspondence: Dr MJ Owens, Department of Psychiatry and Behavioral Sciences, Emory University, I0I Woodruff Circle, Suite 4000, Atlanta, GA 30322, USA, Tel: + 404727 4059, Fax: 404727 3233, E-mail: mowens@emory.edu

Received 6 September 2007; revised 28 February 2008; accepted 29 February 2008
}

Recently, there is an increasing appreciation that antidepressant transporter selectivity is relative and is dependent upon the concentration of drug at the transporter, which is ultimately related to dose (Owens, 2004). There is continuing controversy as to whether a combination of both SERT and NET inhibition represents a more effective antidepressant treatment than drugs that target a single neurotransmitter system, particularly for severe or refractory depression (Seth et al, 1992; Nelson, 1998; Thase et al, 2001; Nemeroff, 2006). In an open-label study, combination treatment with desipramine, a relatively selective inhibitor of the NET, and the SSRI fluoxetine led to a more rapid onset of antidepressant efficacy than either treatment alone (Nelson et al, 1991). More recently, this group reported that the combination of fluoxetine plus desipramine was significantly more likely to result in remission than either drug alone in a double-blinded study (Nelson et al, 2004). Similarly, a combination of nortriptyline and fluoxetine or sertraline was more effective than the use of one of these 
agents alone in ameliorating treatment-resistant depression (Seth et al, 1992). A pooled analysis of all of the Wyethsponsored venlafaxine clinical trials revealed that remission rate differences for venlafaxine $v s$ SSRI therapy were small but statistically significant, largely attributed to venlafaxinefluoxetine differences (Nemeroff et al, 2008).

Venlafaxine is classified as a dual SERT/NET inhibitor that does not posses the anticholinergic, antihistaminergic, and antiadrenergic properties of the dual reuptake inhibitor tricyclic antidepressants such as imipramine and amitriptyline. Multiple investigators have demonstrated that venlafaxine and its active metabolite, $O$-desmethylvenlafaxine (ODV), are relatively weak inhibitors of the NET in vitro (Owens et al, 1997; Tatsumi et al, 1997; Beique et al, 1998). However, partly because of its low serum protein binding, it is widely accepted that venlafaxine does possess dual uptake blocking properties in vivo, particularly in the upper range of dosage.

Paroxetine has been classified as an SSRI on the basis of its very high affinity for the SERT $\left(K_{i}=65 \mathrm{pmol} / \mathrm{l}\right)$, although evidence from several laboratories has indicated that paroxetine also shows moderate affinity for the NET ( $K_{i}=\sim 40-85 \mathrm{nmol} / \mathrm{l}$ ) (Owens et al, 1997, 2001; Tatsumi et al, 1997; Beique et al, 1998). Laboratory animal studies have confirmed that after systemic administration, paroxetine partially inhibits the NET in rat brain homogenates (Owens et al, 2000). Thus, at higher concentrations/doses paroxetine loses its SERT selectivity and, like venlafaxine, may act as a dual serotonin/norepinephrine uptake inhibitor (SNRI). Indeed, our group has previously reported that paroxetine, beginning at a dose of $40 \mathrm{mg} / \mathrm{day}$, partially inhibits the NET while producing $>80 \%$ SERT inhibition (Gilmor et al, 2002). That initial study, a subsequent small study (Davidson et al, 2005), and the present one used a modified monoamine uptake assay that measures SERT and NET inhibition using serum obtained from blood samples of patients treated with escalating doses of the medication under investigation. This method maintains the important equilibrium between free and serum protein-bound drug, hence modeling in vivo conditions where only free drug is generally considered accessible to the brain and clinically relevant sites of action.

The present study tested the hypothesis that both venlafaxine and paroxetine partially inhibit the NET while producing robust $(>80 \%)$ SERT inhibition in a dose-dependent manner in subjects with MDD.

\section{MATERIALS, PATIENTS, AND METHODS}

\section{Subjects}

Patients were enrolled at 7 clinical research centers in the United States from April to December, 2003. INC Research Inc. (Raleigh, NC) provided managerial oversight of the clinical research centers. The study was conducted in accordance with Good Clinical Practice guidelines and the Declaration of Helsinki (1996). The protocol and informed consent were approved by the Institutional Review Boards or Ethics Committees before each center's initiation.

Male and female subjects (18-65 years) meeting diagnostic criteria for MDD were eligible (American Psychiatric Association, 1994). The diagnosis of MDD was made by the principal investigator using the Mini International Neuropsychiatric Interview (MINI) - a structured diagnostic interview for DSM-IV (Sheehan et al, 1998). A total score of $\geqslant 20$ on the Montgomery-Asberg Depression Rating Scale (MADRS) (Montgomery and Asberg, 1979) was required at screening and baseline. Patients were excluded if they had a clinically predominant axis I disorder other than MDD. Other key exclusion criteria were: history of unresponsiveness to either paroxetine or venlafaxine or exhibited prior hypersensitivity/intolerance to either paroxetine $\mathrm{CR}$ or venlafaxine XR, substance abuse/dependence, prior nonresponse to SSRIs, suicidal/homicidal risk, concurrent psychotherapy or psychotropic pharmacotherapy, or any serious medical condition or clinically significant finding in the screening or baseline evaluation that would preclude the administration of paroxetine CR or venlafaxine XR.

Patients were excluded if they required concomitant therapy with psychoactive medication or patients who have taken other psychoactive medication within the time frames specified below prior to the screening visit: antidepressants other than MAOIs or fluoxetine (eg, tricyclic antidepressants, SSRIs, and NSRIs), lithium and oral antipsychotics - 14 days ; hypnotics, benzodiazepines, and all other sedatives (including chlorpheniramine and other sedating antihistamines) - 14 days; fluoxetine, MAOIs - 4 weeks; depot neuroleptics - 12 weeks; any CNS-active herbal preparations/supplement (eg, St John's wort, kava kava, etc.) - 14 days.

\section{Study Design}

This GSK supported collaborative research trial (study 826) was a prospective, multicenter, 8-week, randomized, double-blind, parallel group, forced-titration of paroxetine CR (12.5-75 mg/day) or venlafaxine XR (75-375 mg/day). Patients meeting eligibility criteria at baseline were randomized $(1: 1)$ to receive over-encapsulated PAR or VEN tablets using a computer-generated randomization list. For the first week, patients received PAR $12.5 \mathrm{mg} /$ day or VEN $75 \mathrm{mg} /$ day. Patient's dose was force titrated upward at weekly and bi-weekly intervals to a maximum dosage of either PAR $75 \mathrm{mg} /$ day or VEN $375 \mathrm{mg} /$ day as shown in Table 1. Patients unable to tolerate dose increases were withdrawn from the study. On-treatment study assessments were scheduled at the end of weeks $1,2,3,4,5,6,7$, and 8 or upon early withdrawal. Assessments of efficacy, safety, and tolerability were conducted at each visit. Weekly blood samples were obtained for measuring serum drug concentrations and for transporter occupancy measurements (see below). Drug concentrations were analyzed by an experienced laboratory (Quest Diagnostics Clinical Trials, Los Angeles, CA). The limit of detection for paroxetine, venlafaxine, and ODV was $10 \mathrm{ng} / \mathrm{ml}$.

\section{Efficacy Assessments}

The primary objective was to estimate and compare PARand VEN-induced NET and SERT inhibition in patients with MDD using an ex vivo method described previously (Gilmor et al, 2002; Davidson et al, 2005); details below). The relationship between percentage inhibition of the NET and the SERT and medication dosage and serum drug 
Table I Subject Treatment and Dosage Over Time

Daily dosage

Treatment

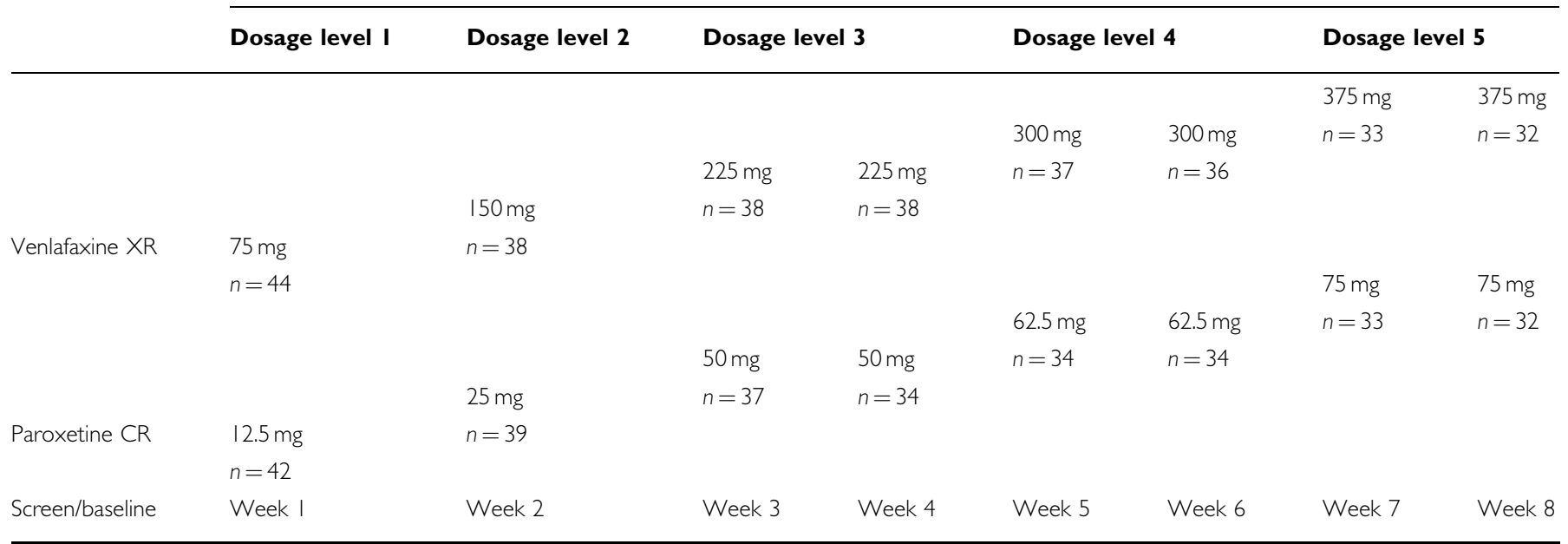

Each subject received five different dosage levels of venlafaxine XR or paroxetine CR over an 8-week treatment period. The weeks of treatment are shown at the bottom of each column. The number of subjects ( $n$ ) remaining within the study at each time point are listed for each medication at each week.

concentration were determined. Clinical efficacy measures were secondary objectives in this study. The key measure of efficacy was change from baseline in MADRS total score at week 8 last observation carried forward (LOCF) endpoint. Additional measures of efficacy (also based on week 8 LOCF endpoint) were: proportion of Clinical Global Impression global improvement item (CGI-I) responders (Guy, 1976) defined as a score of 1 (very much improved) or 2 (much improved change from baseline) on the CGI-S (Guy, 1976). Post hoc analyses were conducted to determine the proportion of responders (defined as a $\geqslant 50 \%$ reduction in MADRS total score) and remitters (defined as a MADRS score $\leqslant 10$ ) in each treatment group. A psychiatrist, clinical psychologist, or psychometrician with at least 2 years experience in treating patients conducted all efficacy assessments.

\section{Antidepressant Response}

All patients who were randomized, received at least one dose of study medication and had at least one post-baseline efficacy assessment, were included in the modified intentto-treat (ITT) efficacy analyses. Exploratory analysis of clinical efficacy data (secondary objectives in this study) was performed using $t$-tests (two-sided, $P<0.05$ level of significance). Analysis of change from baseline in MADRS was performed separately at each post-baseline time point using the proc glm procedure in $S A S^{\circledR}$ version 8.2. There was no adjustment for any covariates or any repeated measures analysis. Patients withdrawing before week 2 without MADRS assessments are not included in the analyses of the MADRS. The analyses on observed data were repeated using the LOCF approach to impute missing values. Subjects with a CGI global improvement rating of 'much improved' or 'very much improved' were categorized as responders. The responder rates at each post-baseline visit (study weeks 1 through 8) were compared between the treatment groups in an exploratory fashion. The comparisons were performed using the Fisher's Exact Test (two-sided). In addition, 95\% confidence intervals (CI) for the differences in responder rates were estimated using the normal approximation to the binomial distribution. Analyses were performed using proc freq in $\mathrm{SAS}^{\circledR}$ version 8.2. All patients randomized at baseline were used in the ITT safety analyses. The number (percentage) of patients in each treatment group (both combined and by dosage level) with treatment emergent adverse experiences were compared for overall incidence.

\section{Ex vivo $\left[{ }^{3} \mathrm{H}\right]$-Serotonin and $\left[{ }^{3} \mathrm{H}\right]-$ Norepinephrine Uptake and Analysis}

The assay method has been described in detail previously (Gilmor et al, 2002). Positive control sample wells consisted of normal human serum containing either $300 \mathrm{nmol} / \mathrm{l}$ paroxetine or $3 \mu \mathrm{mol} / \mathrm{l}$ desipramine for the $\left[{ }^{3} \mathrm{H}\right]$-serotonin and $\left[{ }^{3} \mathrm{H}\right]$-norepinephrine uptake assays, respectively.

Individual points from patient data were obtained by calculating the mean of replicate values $(5-7$; minimum of 3) from a given sample as the percent baseline of the predrug treatment sample mean (baseline) for that individual. An individual replicate was excluded from mean sample calculation if it was significantly different than all other replicates (eg $>3 \mathrm{SD}$ away from sample mean). Percent occupancy is calculated as 100-percentage of baseline. Concentration-uptake curves were generated with the nonlinear, curve-fitting program PRISM 3.0 (GraphPad, San Diego, CA) by using a one-site competition curve to describe drug-transporter interactions (Kenakin, 1997). Because drug serum concentrations vary widely among patients at identical dosages, competition curves were generated by treating the data points from all analyzed individuals in each treatment group as individual data points (ie, a certain amount of transporter blockade at a given serum drug concentration), rather than generating a curve for each patient and then averaging these curves. Means are presented with standard deviations. 


\section{Statistical Analysis}

INC Research, Inc. (Raleigh, NC) provided professional statistical analysis of the efficacy and tolerability data. Analysis of all serum data was conducted by the Emory University investigators using SigmaStat 3.0 and SPSS (SPSS Inc., Chicago, IL) and PRISM 3.0 (GraphPad, San Diego, CA).

\section{RESULTS}

\section{Serum Concentrations and Estimated Transporter Inhibition}

As shown in Figure 1, mean serum concentrations of paroxetine and combined venlafaxine plus ODV increased with increasing dosage $(P<0.001$; one-way repeated measures ANOVA). Because venlafaxine and ODV have essentially identical affinities at the SERT and NET (Owens et al, 1997), their serum concentrations were combined. As shown in the insets of Figure 1, there is a high degree of inter-individual variability in the resultant steady-state serum concentrations produced by identical dosages.

As predicted from in vitro studies of affinity, both medications dose-dependently inhibited the SERT (Figure 2 top) and NET (Figure 2 bottom) (one-way repeated measures ANOVA; $P<0.001$ for each medication and for both SERT and NET). At the doses tested in this particular study, maximal mean SERT inhibition was estimated to be $90 \%$ (SD 7) and $85 \%$ (SD 10) in the paroxetine and venlafaxine groups, respectively. At week 8 , the maximal inhibition of the SERT produced by paroxetine was significantly greater than that produced by venlafaxine (Figure 2; $p=0.038$, Student $t$-test with Welch's correction, $\mathrm{t}=2.15, \mathrm{df}=42,95 \%$ CI 9.81-0.30). Similarly, maximal mean NET inhibition was estimated to be $36 \%$ (SD 19) and 60\% (SD 13) in the highest dosage paroxetine and venlafaxine treatment groups at week 8 , respectively (Figure 2; $P<0.001$, Student $t$-test with Welch's correction, $\mathrm{t}=5.31, \mathrm{df}=46,95 \%$ CI 14.7-32.7).

Because transporter inhibition is directly related to free drug concentrations within the extracellular water surrounding neurons and that this is more closely related to serum drug concentrations than to drug dosage, we calculated the relationship between serum drug concentrations and SERT and NET inhibition using all available data points and classic drug-receptor curve fitting software (onesite competition curve, PRISM 3.0 (GraphPad, San Diego, $\mathrm{CA})$ ) (Figure 3). As shown in Figure 3, the vast majority of all data points, which included all patient samples in which a quantifiable serum drug concentration could be attained, revealed considerable ( $>70 \%)$ SERT inhibition. These data reveal that the inhibition constant $\left(K_{i}\right)$ value, which represents the mean serum concentration necessary to inhibit $50 \%$ of available transporters, is $9 \mathrm{ng} / \mathrm{ml}(23 \mathrm{nmol} / \mathrm{l}$; $95 \%$ CI $21-25 \mathrm{nmol} / \mathrm{l})$ and approximately $85 \mathrm{ng} / \mathrm{ml}$ $(315 \mathrm{nmol} / \mathrm{l} ; 95 \%$ CI $294-338 \mathrm{nmol} / \mathrm{l})$ for paroxetine and total venlafaxine concentrations, respectively. Although neither medication is as efficacious in inhibiting the NET compared to the SERT, both paroxetine and venlafaxine produced a concentration-dependent inhibition of the NET (Figure 3). For NET inhibition, $K_{i}$ values were serum concentrations of $227 \mathrm{ng} / \mathrm{ml} \quad(690 \mathrm{nmol} / \mathrm{l} ; 95 \%$ CI $590-$ $805 \mathrm{nmol} / \mathrm{l})$ and approximately $325 \mathrm{ng} / \mathrm{ml}$ (1 $204 \mathrm{nmol} / \mathrm{l}$;
95\% CI $1126-1288 \mathrm{nmol} / \mathrm{l})$ for paroxetine and 'total venlafaxine', respectively.

\section{Treatment Response}

In total, 86 patients were randomized, of which 55 (64.0\%) were female subjects and $31(36.0 \%)$ were male subjects. Because five of the randomized patients did not have a postbaseline efficacy assessment, the evaluable population (modified ITT) consisted of 81 (40 paroxetine CR patients and 41 venlafaxine XR patients) patients. Demographic and baseline characteristics of the ITT population are available upon request.

The mean MADRS total score at baseline was 28.6 (SD 5.05) for PAR and 28.6 (SD 5.97) for VEN, indicative of moderate-to-severe MDD symptomatology. This level of severity was also reflected in the baseline CGI-S ratings for PAR (mildly Ill $=2.5 \%$, moderately $\mathrm{Ill}=62.5 \%$, markedly $\mathrm{Ill}=27.5 \%$, and severely or among the most extremely $\mathrm{Ill}=$ $7.5 \%$ ) and VEN (mildly Ill $=0 \%$, moderately $\mathrm{Ill}=56.1 \%$, markedly $\mathrm{Ill}=31.7 \%$, and severely or among the most extremely $\mathrm{Ill}=12.2 \%$ ).

A total of $74.4 \%(64 / 86)$ of patients (ITT population) completed the 8-week, double-blind phase. The percentage of patients who withdrew for any reason was $27.3 \%(12 / 44)$ in the VEN group and $23.8 \%(10 / 42)$ in the PAR group. The proportion of patients withdrawn due to an AE in the VEN group was $9.1 \%(4 / 44)$, compared with $4.8 \%(2 / 42)$ in the PAR group.

Overall, at week $8,76 \%(32 / 42)$ of PAR patients received the maximum daily dose ( $75 \mathrm{mg}$ per day) compared with $73 \%(32 / 44)$ of VEN-treated patients who received the maximum daily dose ( $375 \mathrm{mg}$ per day). The adjusted mean change from baseline at week 8 LOCF endpoint in MADRS total score was -16.7 points (SE 8.59) for patients randomized to PAR and -17.3 points (SE 8.99) for those randomized to VEN. The adjusted mean difference between the treatment groups, 0.60 points, was not statistically significant (95\% CI $-3.42,4.54, p=0.784)$ (Table 2). At week 8, the percent CGI-I response rate (LOCF) was $78.9 \%$ for VEN and $67.5 \%$ for PAR. This difference was also not statistically significant ( $95 \%$ CI $-30.9,8.0 ; p=0.312$ ).

Two post hoc LOCF analyses (using a two-tailed Fisher's Exact Test) were conducted: (1) the proportion of responders in each treatment group achieving at least a 50\% reduction in MADRS total score (from baseline), and (2) the proportion of patients in remission at week 8 LOCF defined as a MADRS score less than or equal to 10 . Although the VEN group showed slightly greater numerical improvement for both response (VEN vs PAR $71.1 v s$ $64.9 \%, p=0.626$ ) and remission (VEN vs PAR 63.2 vs $45.9 \%$, $p=0.167)$, the differences were not statistically significant.

Overall, similar proportions of patients on PAR and VEN had at least one treatment emergent AE (81.0\% [34/42] for PAR vs 81.8\% [36/44] for VEN). Most of the AEs were mild to moderate in intensity and did not lead to withdrawal (details available upon request).

\section{Estimated Transporter Inhibition and Treatment Response}

The present study was neither primarily designed nor powered to determine the relationship between the magnitude 


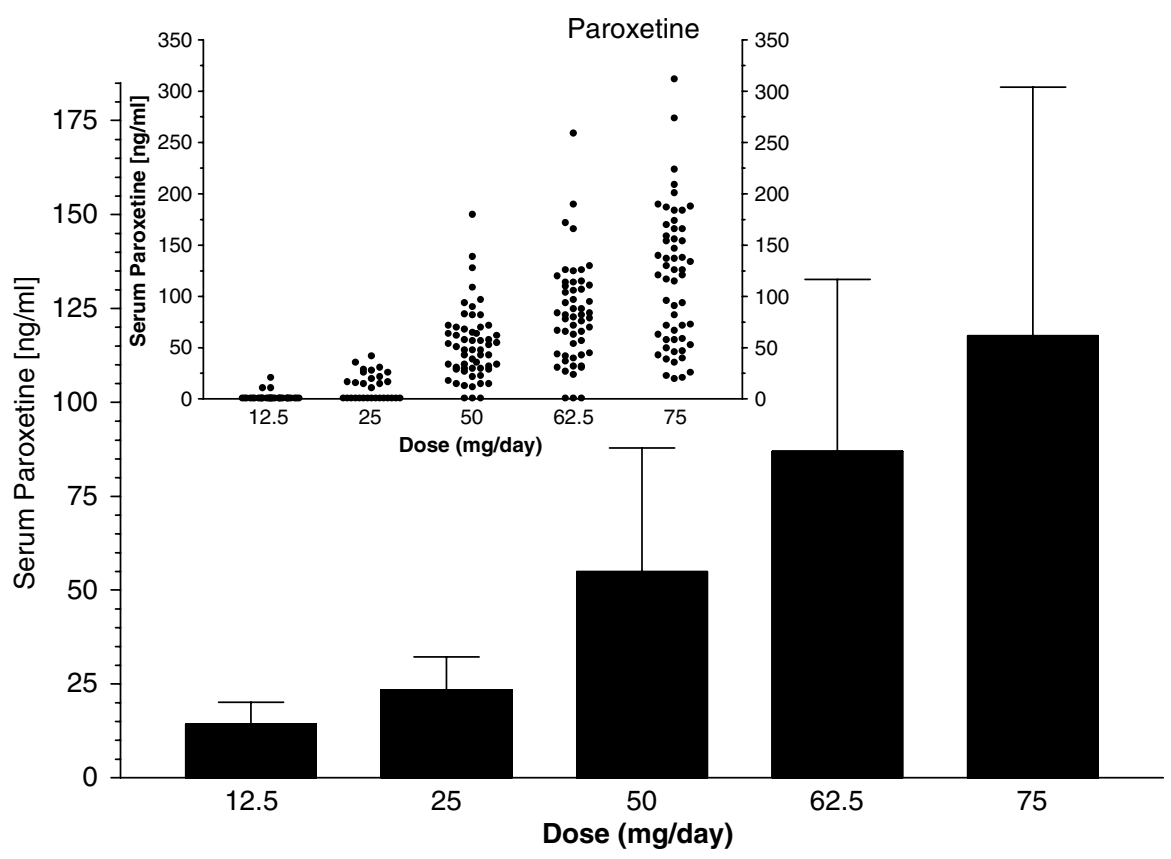

Venlafaxine $+O$-desmethylvenlafaxine

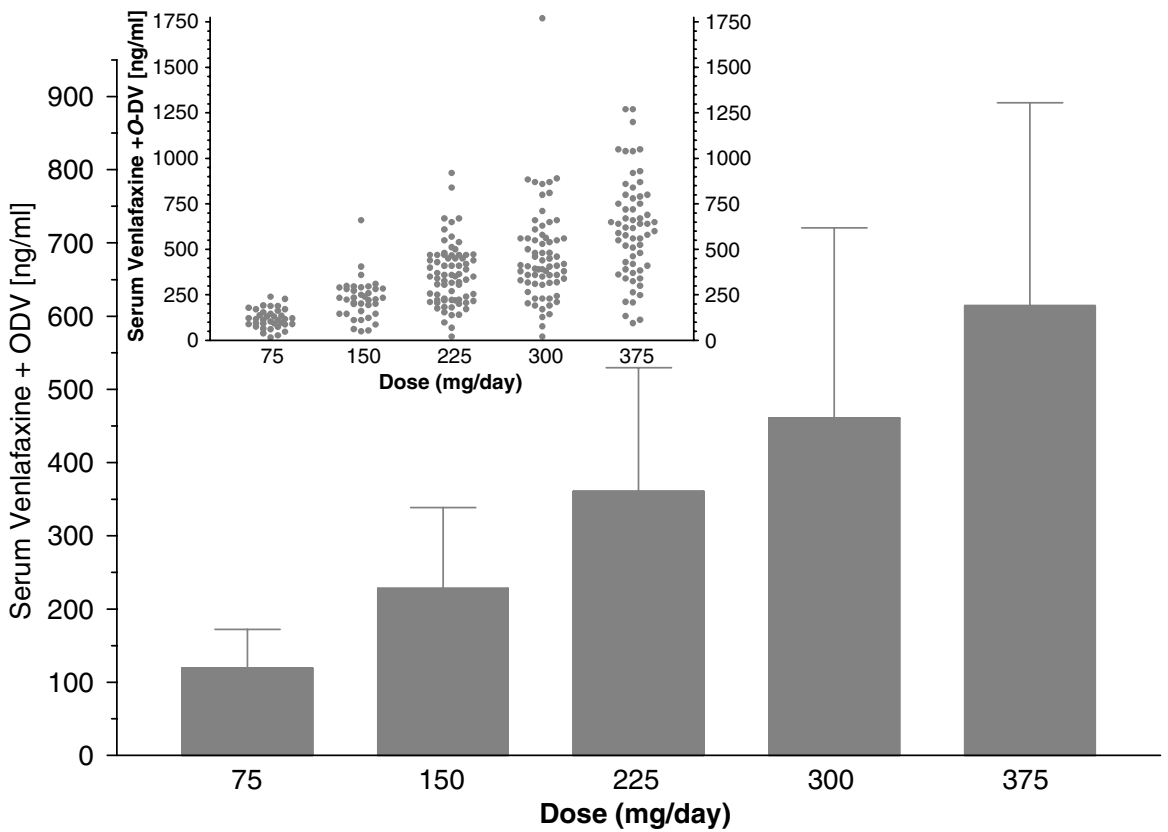

Figure I Paroxetine and combined venlafaxine and O-desmethylvenlafaxine (ODV) serum concentrations as a function of dose. Following at least I week of therapy at each dose, mean serum concentrations (mean \pm SD) increased as a function of dose. However, there is wide inter-individual scatter at identical doses (inset). Data points in the scatterplot at $0 \mathrm{ng} / \mathrm{ml}$ represent samples below the analytic limit of detection (I0 ng/ml; Quest Diagnostics) and may represent low concentrations associated with low doses or non-compliance. There were no differences between the same dose of drug at different time points (eg, weeks 7 and 8; one-way ANOVA with Tukey post-hoc test). Data from identical doses at different time points were collapsed into single bars for display purposes. Bar data only used data points with measurable serum concentrations. $\log [\mathrm{mol} / \mathrm{l}]$ serum concentrations of paroxetine $=\log ([\mathrm{ng} / \mathrm{ml}] /$ 329400 000). Venlafaxine and ODV have essentially identical affinities at the SERT and NET (Owens et al, 1997) and can be combined on a molar basis to yield a total active amount of drug. Log[mol/l] serum concentrations of combined venlafaxine + ODV $\approx \log ([\mathrm{ng} / \mathrm{ml}] / 270400000)$.

of individual, or combined, SERT or NET inhibition and clinical response or remission. Nevertheless, we plotted the magnitude of SERT or NET inhibition and treatment response in the subjects who both completed the full 8-week treatment and provided a serum sample for SERT and NET occupancy at this time point. No significant interactions (two-way
ANOVA) were observed between SERT or NET inhibition and treatment response to paroxetine or venlafaxine (Figure 4). Similarly, no differences in transporter inhibition and treatment response were observed when all subjects were examined on the basis of SERT and NET inhibition only (bottom graph of Figure 4). 

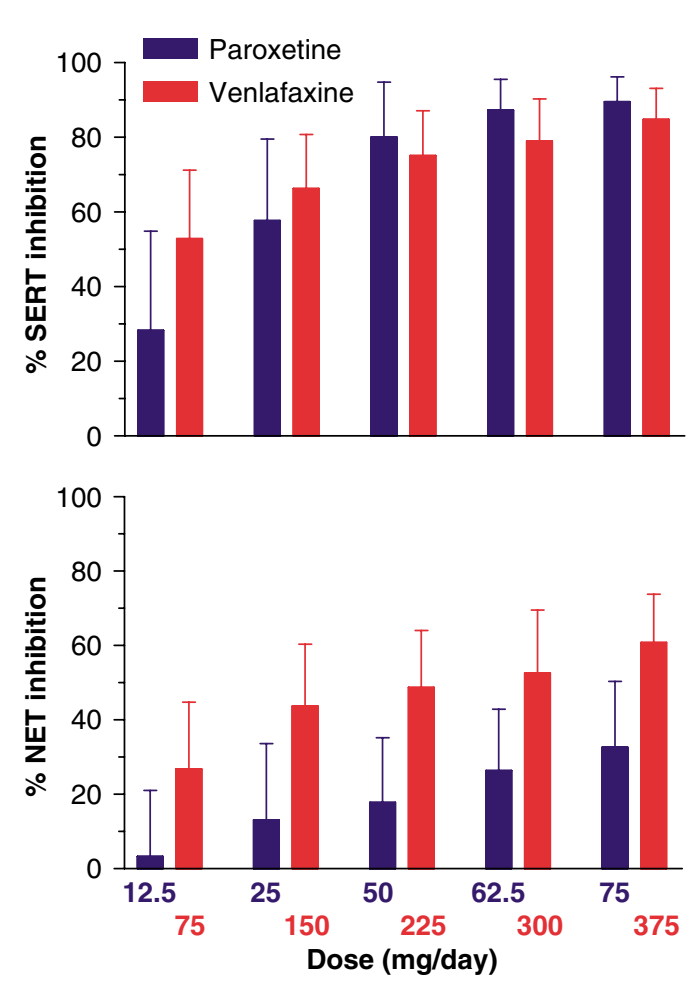

Figure 2 Estimated CNS SERT and NET inhibition by paroxetine and venlafaxine. Percent SERT inhibition (ie, occupancy) was dose-dependently increased by both paroxetine and venlafaxine (mean $\pm \mathrm{SD}$; one-way repeated measures ANOVA, $P<0.00 \mathrm{I}, \mathrm{F}=89.0$ [paroxetine], $\mathrm{F}=53.7$ [venlafaxine]). There were no differences between the same dose of drug at different time points (eg, weeks 7 and 8). Within each drug, the lowest dose was significantly different than every other dose and doses separated by $25 \mathrm{mg} /$ day (paroxetine) or $150 \mathrm{mg} /$ day (venlafaxine) were significantly different than each other $(P<0.05$; Tukey test). Data from identical doses at different time points were collapsed into single bars for display purposes only. Although the difference was only $5 \%$ occupancy, direct comparison of the week 8 data revealed that paroxetine $75 \mathrm{mg} /$ day produced greater SERT inhibition than venlafaxine $375 \mathrm{mg} /$ day $(p=0.002$, Student $t$-test with Welch's correction, $t=2.15, d f=46, C l 9.8 I-0.30)$. These data are based upon dosage only and include samples for which paroxetine was below the limit of detection. Percent NET inhibition (ie, occupancy) was dosedependently increased by both paroxetine and venlafaxine (mean \pm SD; one-way repeated measures ANOVA $P<0.00 \mathrm{I}, F=15.5$ [paroxetine], $F=33.1$ [venlafaxine]). There were no differences between the same dose of drug at different time points (eg, weeks 7 and 8). Within each drug, the lowest dose was significantly different than every other dose and doses separated by $25 \mathrm{mg} /$ day (paroxetine) or $150 \mathrm{mg} /$ day (venlafaxine) were significantly different than each other $(P<0.05$; Tukey test). Data from identical doses at different time points were collapsed into single bars for display purposes only. Direct comparison of the week 8 dose of each drug used in this study revealed that venlafaxine $375 \mathrm{mg} /$ day produced greater NET inhibition than paroxetine $75 \mathrm{mg} /$ day $(P<0.00$ I, Student $t$-test with Welch's correction, $t=5.3, d f=46,95 \% \mathrm{Cl}$ |4.7-32.7). These data are based upon dosage only and include samples for which paroxetine was below the limit of detection.

\section{DISCUSSION}

Transporter and receptor occupancy has become an increasingly important area of research in understanding the therapeutic mechanisms of antidepressant and antipsychotic drugs. Over the past several years, Meyer and colleagues have performed PET scans of SERT availability in patients treated with SSRIs (Meyer et al, 2001, 2004). Of particular interest, dose- and concentration-occupancy curves revealed that doses commonly considered therapeutically effective produced approximately $80 \%$ SERT occupancy. This was consistent across all SSRIs. Moreover, some subjects clearly had lower SERT occupancy, though the therapeutic outcome of those individuals was not reported. Meyer and colleagues found no relationship between striatal occupancy and percent change in the HAMD score from scan 1 (pre-drug baseline) to scan 2 (steady-state drug treatment); however, it should be noted that striatal occupancy following this standardized drug treatment occurred across a small window rather than a large (eg, 0-100\% occupancy) window in which clear relationships between occupancy, or thresholds of necessary occupancy, and variations in clinical response may be more easily observed. The present studies are the first to measure both SERT and NET occupancy provisionally needed for efficacy in a larger population of depressed subjects. These data may be extremely valuable in monitoring patient compliance, the need for dosage adjustment and, in the case of adequate occupancy without therapeutic response, information that provides a rational decision to switch medication class or initiate other treatment options. Unfortunately, the costs and limited availability of PET facilities renders SERT occupancy measurements impractical for the vast majority of physicians.

We have developed a unique method in which to measure the magnitude of 5-HT or norepinephrine transporter occupancy in antidepressant-treated patients by exposing cells transfected with the human SERT or NET to the patient's serum after steady-state is attained (Gilmor et al, 2002; Davidson et al, 2005). This allows for a reliable and quantitative method to estimate in any given patient the magnitude of SERT or NET inhibition. Because only the unbound, 'free' fraction of the drug interacts with the transfected cells, differential protein binding of antidepressants is not a confound in these studies.

It is assumed that the free drug concentration as assessed with this novel method is approximately the same drug concentration available to enter the brain, and therefore corresponds to brain extracellular drug water concentrations (Frazer, 2001). Classical receptor pharmacological theory predicts that receptor (or transporter) occupancy and biological action is a concentration-dependent phenomenon (Kenakin, 1997). Depending upon the affinity of each individual drug, there is a direct correlation between receptor occupancy (a function of drug concentration) and biological response. The shapes of these curves may differ depending upon the specific properties of the individual drug (eg, full $v s$ partial agonist) and whether there exist 'spare' receptors. Until recently, little or no data were available regarding the magnitude of SERT blockade necessary for an antidepressant response in humans. Moreover, the percentage of transporter occupancy that occurs as a function of antidepressant dose or serum drug concentration was not known.

Knowledge of the concentration of antidepressants in the extracellular fluid surrounding neurons could theoretically be used to estimate transporter blockade based upon the results of in vitro binding studies (Owens et al, 1997, 2001; Tatsumi et al, 1997; Beique et al, 1998) and central nervous system (CNS) pharmacokinetics (Gjedde et al, 2000). It is 

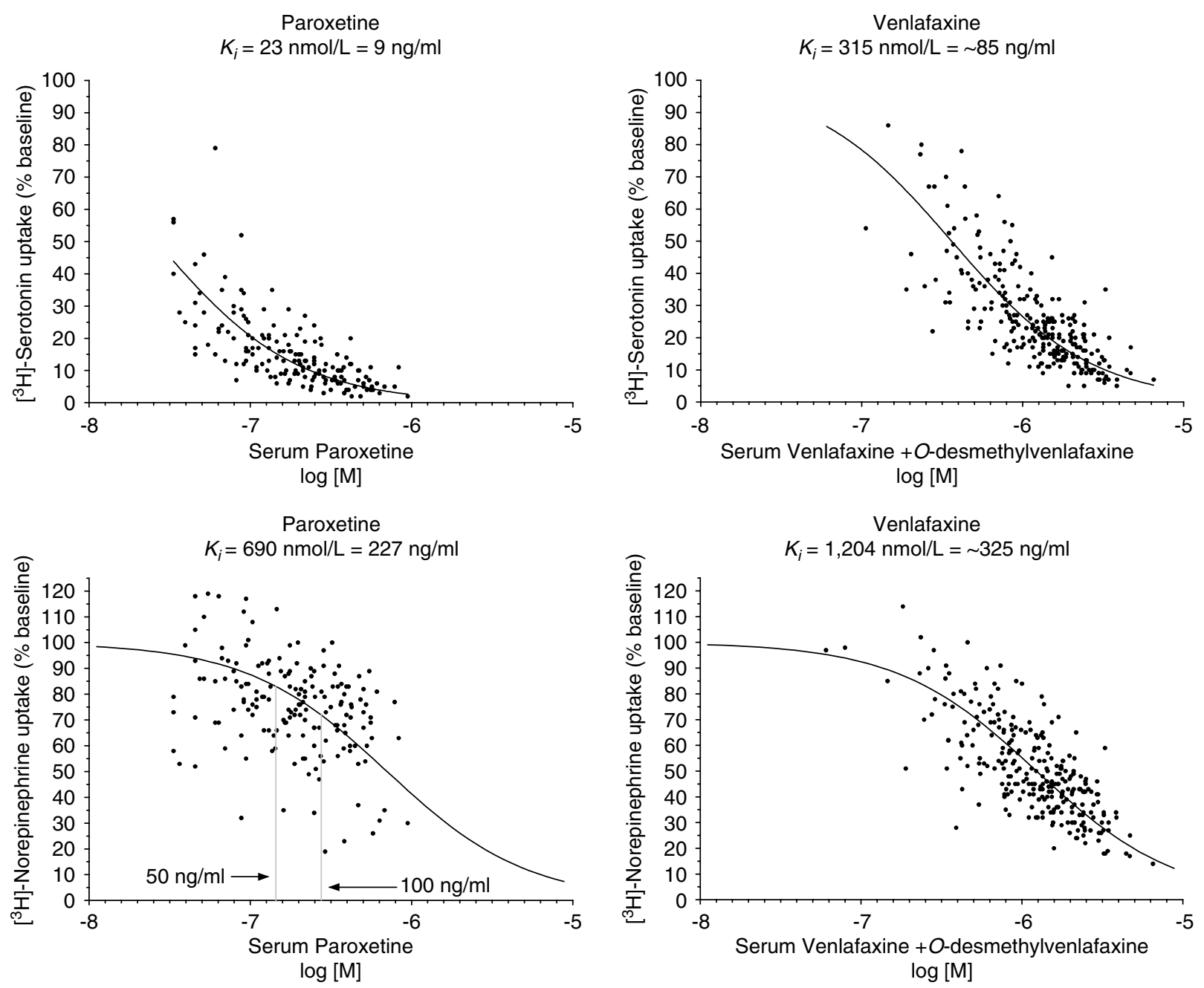

Figure 3 Relationship between SERT and NET occupancy and serum concentrations of paroxetine and venlafaxine + O-desmethylvenlafaxine (ODV) in patients with major depressive disorder. Curves were generated using all data points in which accurately quantifiable medication was present in serum. Venlafaxine and ODV possess identical affinities for the SERT and NET and are combined to give a total active molar concentration in serum. The molecular weights of venlafaxine and ODV are 277 and 263, respectively. We added the individual molar concentrations of each drug together to provide a total molar concentration but used a value of 270 to convert combined molar concentrations of these two medications into a ng/ml estimate of the $K_{i}$ value. Classic one-site competition curves used to describe drug-transporter interactions resulted in goodness of fit ( $\left.r^{2}\right)$ and $95 \%$ confidence intervals (Cl) of: paroxetine at the SERT $\left(r^{2}=0.49,95 \% \mathrm{Cl}=2 \mathrm{I}-25 \mathrm{nmol} / \mathrm{l}\right)$, venlafaxine at the SERT $\left(r^{2}=0.62,95 \% \mathrm{Cl}=294-338 \mathrm{nmol} / \mathrm{l}\right)$, paroxetine at the NET $\left(r^{2}=0.08,95 \%\right.$ $\mathrm{Cl}=590-805 \mathrm{nmol} / \mathrm{l})$ and venlafaxine at the NET $\left(r^{2}=0.54,95 \% \mathrm{Cl}=|| 26-1288 \mathrm{nmol} / \mathrm{l}\right)$. For comparison, regression analysis of serum paroxetine concentrations of 25,50 , and $100 \mathrm{ng} / \mathrm{ml}$ correspond with 94,89 , and $80 \%$ of baseline uptake or 6 , II, and $20 \%$ NET occupancy, respectively. Log [mol/I] serum concentrations of paroxetine $=\log ([\mathrm{ng} / \mathrm{ml}] / 329400$ 000). Log $[\mathrm{mol} / \mathrm{l}]$ serum concentrations of venlafaxine $=\log ([\mathrm{ng} / \mathrm{ml} / 277400000) . \mathrm{Log}[\mathrm{mol} / \mathrm{l}]$ serum concentrations of ODV $=\log ([\mathrm{ng} / \mathrm{ml} / 263400000)$.

widely believed that cerebrospinal fluid (CSF) concentrations of drug represent an accurate estimate of drug concentrations in the extracellular matrix surrounding neurons. However, there is surprisingly little data available regarding CSF concentrations of new generation antidepressants as a function of drug dosage or serum concentrations. Of the studies that exist, several have shown a strong correlation between CSF and serum concentrations of several other classes of psychopharmacological agents. For example, a nearly perfect correlation between CSF concentrations and predicted 'free' serum concentrations exists for imipramine and desipramine (Muscettola et al, 1978). There is also a significant correlation for other tricyclic antidepressants (Hanin et al, 1985; Potter et al, 1985) and the typical antipsychotic drug haloperidol (Forsman and
Ohman, 1997; Linkowski et al, 1984). Similar findings are present, albeit with much smaller data sets, for SSRIs including fluoxetine (Martensson et al, 1989) and paroxetine (Lundmark et al, 1994). These data, and others (Rochat et al, 1999; Mahar-Doan et al, 2002; Weiss et al, 2003), suggest that active transport processes do not play any meaningful role.

Measurement of drug concentrations in serum typically reveals only total drug concentration. Although a value representing percent protein bound is available for most drugs, it is apparent that pharmacogenetics, as well as differences in assay technique, result in ranges of protein binding rather than an absolute value. In addition, the same dose of drug can result in widely differing serum concentrations between individuals. Indeed, multi-fold differences 
Table 2 Analysis Results: Secondary Clinical Efficacy Parameters at week 8 LOCF Endpoint (ITT Population)

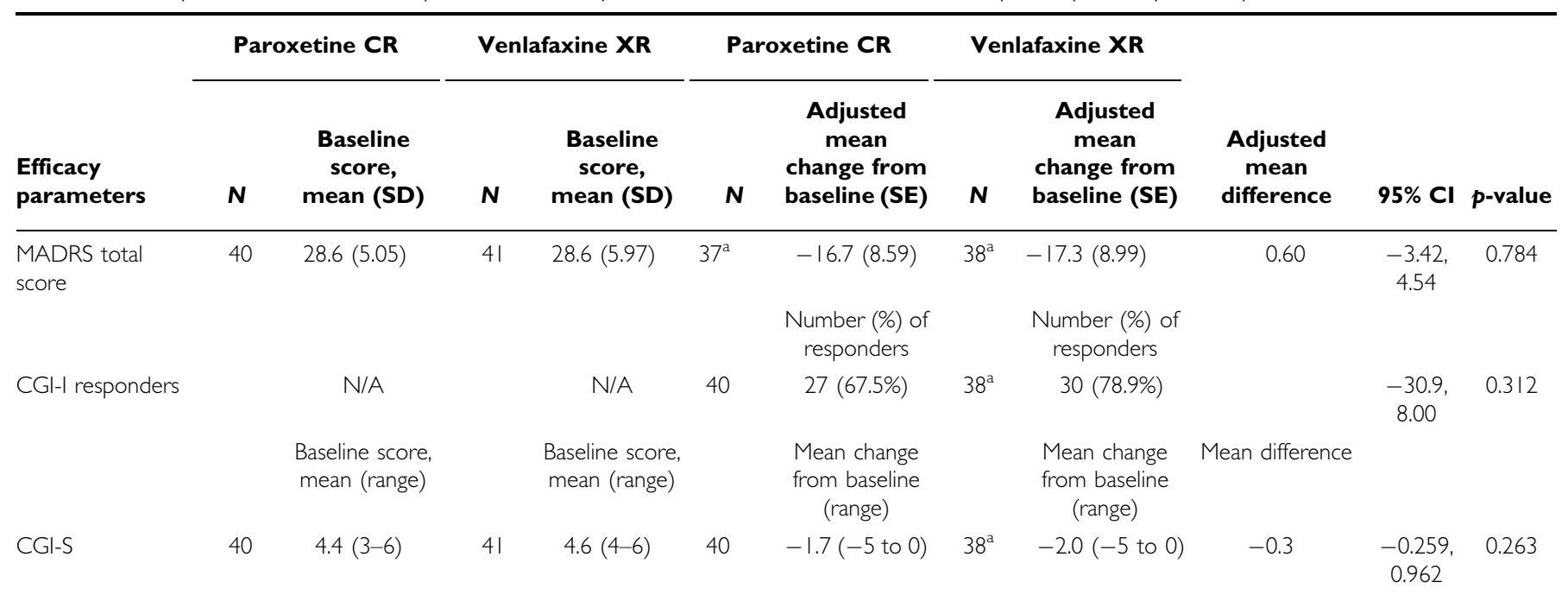

Post hoc MADRS efficacy analyses

\begin{tabular}{lcccccc} 
Response & \multicolumn{7}{c}{$n(\%)$ experiencing $\geqslant 50 \%$ decrease in total score ${ }^{2 b}$} & $p$-value \\
LOCF & $37^{\mathrm{b}}$ & $24(64.9 \%)$ & $38^{\mathrm{a}}$ & $27(71.1 \%)$ & 0.330 & 0.626 \\
Completers & 32 & $24(75.0 \%)$ & 32 & $24(75.0 \%)$ & 0.005 & 1.000 \\
\multicolumn{7}{c}{$n$} \\
$\begin{array}{l}\text { Remission } \\
\text { LOCF }\end{array}$ & $37^{\mathrm{a}}$ & $17(45.9 \%)$ & $38^{\mathrm{a}}$ & $24(63.2 \%)$ & 2.252 & 0.167 \\
Completers & 32 & $17(53.1 \%)$ & 32 & $23(71.9 \%)$ & 2.419 & 0.196
\end{tabular}

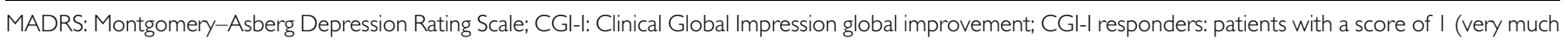
improved) or 2 (much improved), CGl-S: Clinical Global Impression severity of illness; LOCF: Last Observation Carried Forward.

aEleven patients (5 PAR+6 VEN) discontinued from the study before their first scheduled MADRS assessment at week 2, and therefore are not included in the analyses. Seventy-five patients comprise the MADRS evaluable population.

${ }^{b}$ For significance at the 0.05 level, $\chi^{2}$ should be greater than or equal 3.84. No distribution was significant; no comparisons $p<0.05$ using two-tailed Fisher's Exact Test.

in paroxetine and venlafaxine serum concentrations are observed in patients receiving identical doses (Figure 1). Although differences in body mass may play a role in these variances, inter-individual pharmacogenetic differences in genes controlling all aspects of drug availability and kinetics are also important. Thus, simply measuring serum drug concentrations and calculating transporter occupancy based upon reported mean percentage of protein binding and in vitro transporter affinity is clearly not an acceptable method. Indeed, we speculate that a 'therapeutic window' for antidepressants may finally be found if transporter occupancy becomes the important variable rather than serum concentrations.

We have circumvented these confounds by measuring transporter occupancy directly in individual patient serum samples. Because free drug concentrations in serum approximate free drug concentrations in CNS extracellular fluid, we have modified standard in vitro assays for monoamine uptake to closely approximate the conditions in vivo. Rather than neurons being exposed to drug in extracellular fluid, we exposed cell lines expressing either the human SERT or NET directly to human serum containing antidepressants that inhibit SERT and NET function. Serum exhibits the necessary characteristics of osmolarity, glucose, and buffering capacity to sustain active transport. Because the serum is essentially unadulterated (ie, no additional buffers, chemicals, and procedures etc.), the important bound:free ratio is maintained (Gilmor et al, 2002; Davidson et al, 2005). All subjects serve as their own control and therefore, a sample from each subject at baseline (ie, drug-free) serves as $0 \%$ occupancy. Full validation of this assay will require concomitant assessment of transporter occupancy using the ex vivo assay used here and positron emission tomography (PET) imaging which remains the standard for in vivo occupancy data. Such studies are now underway in our laboratory.

As a whole, and as expected, each medication produced dose-dependent increases in SERT and NET inhibition with mean maximal SERT inhibition of $\geqslant 85 \%$ and mean maximal NET inhibition of 36 and $60 \%$ for paroxetine and venlafaxine, respectively, at week 8 (Figure 2). These data should be interpreted with the understanding that at each dose listed in Figure 2, there are wide variations in drug concentrations and, therefore, SERT and NET inhibition. The maximal NET inhibition differed between paroxetine and venlafaxine, but this must also be interpreted with the knowledge of the maximal doses chosen for the end of the study (ie, $75 \mathrm{mg}$ /day paroxetine $\mathrm{CR}$ and $375 \mathrm{mg} /$ day venlafaxine XR). Higher or lower final doses for either medication would have altered the maximal NET 

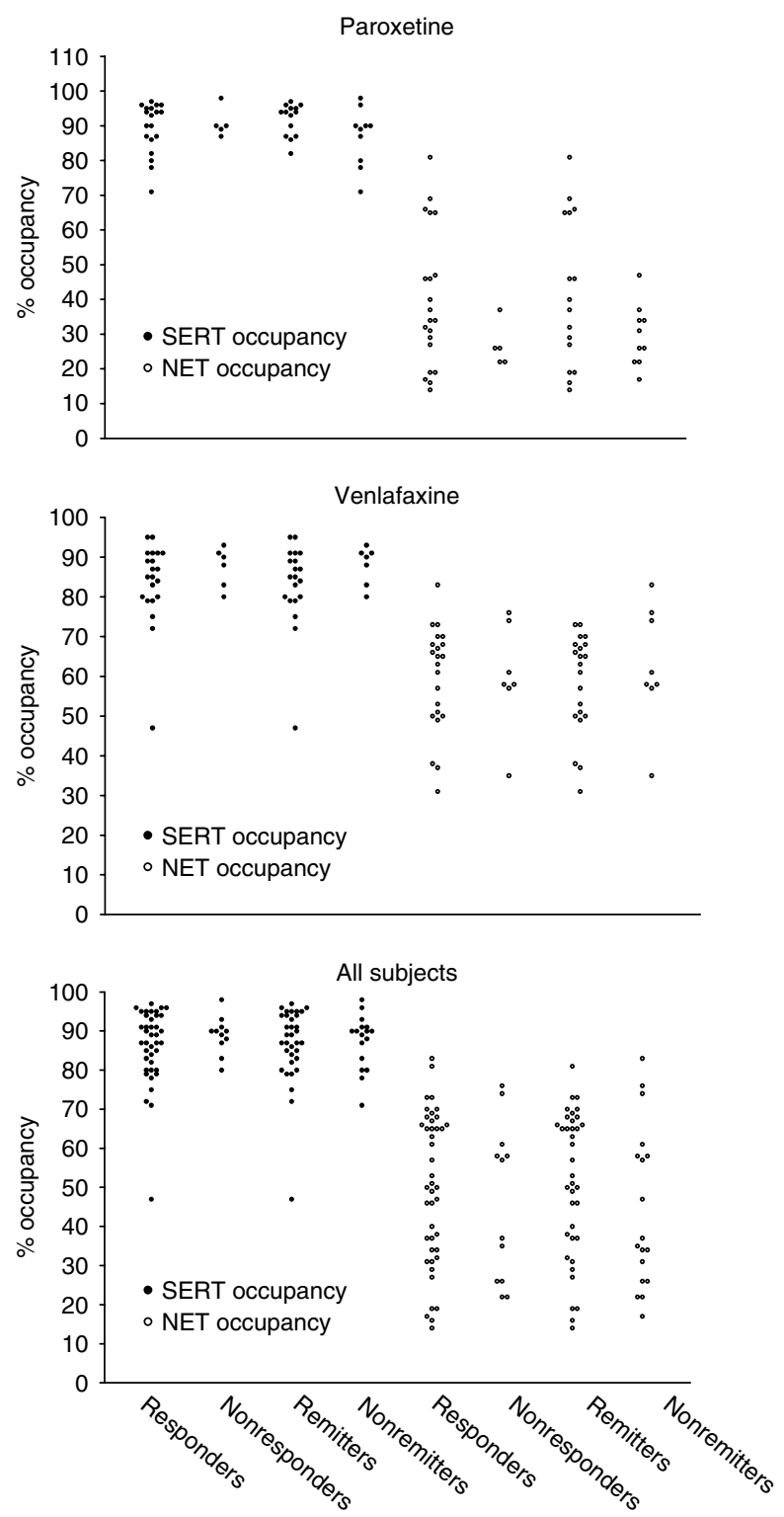

Figure 4 Relationship between treatment response and SERT or NET occupancy at week 8. $Y$ axis is percentage occupancy of the relevant transporter (see SERT and NET designations at bottom of graph). All remitters are also shown as data points under responders and all nonresponders are also shown as data points under nonremitters. Data is only used from patients who completed the entire 8 week protocol and were able to provide serum samples for occupancy estimation at week 8 ( $N=24$ for paroxetine SERT and $N=26$ for paroxetine NET; $N=27$ for venlafaxine SERT, and $N=29$ for venlafaxine NET). The bottom panel does not distinguish between medications but only illustrates response and transporter occupancy. No significant interactions were detected (two-way ANOVA).

inhibition. The replication of our previous findings (Gilmor et al, 2002; Davidson et al, 2005) showing partial NET inhibition with paroxetine provides some rationale for the finding that a $40 \mathrm{mg} /$ day dose of paroxetine was found to be more efficacious in preventing depressive recurrences than a $20 \mathrm{mg} /$ day dose in patients previously treated effectively with a $40 \mathrm{mg} /$ day dose (Franchini et al, 1998). In addition, there is evidence that paroxetine is an effective treatment for refractory depression at higher doses of 30-40 mg/day at which NET inhibition is likely to begin (Tyrer et al, 1987).
Direct comparisons of venlafaxine and paroxetine appeared to favor venlafaxine (Poirier and Boyer, 1999; Ballus et al, 2000). However, as has been pointed out elsewhere (Nemeroff et al, 2008), in these studies low doses of paroxetine were often compared to high doses of venlafaxine, and serum paroxetine concentrations were not reported when doses of 30-40 mg/day were used. In effect, therefore, these studies have compared only the SSRI properties of low doses or probably low serum paroxetine concentrations to venlafaxine's dual transporter inhibition at moderate to high doses in some individuals.

Plotting of all data points based on known serum concentrations in each individual sample and transporter inhibition yields classic drug-receptor competition curves (Figure 3). The data in Figure 3 show that the majority of data points reveal that SERT inhibition is approaching or greater than $80 \%$ (20\% of baseline along $Y$ axis), which appears to be a threshold for efficacy (Meyer et al, 2001, 2004). These data verify that both drugs can be effective (ie, provide $80 \%$ SERT inhibition) even at low doses in some individuals.

These data also show that neither of the drugs produce the magnitude of NET inhibition that they provide of SERT inhibition, though both agents again display classic pharmacological binding curves as expected. It is clear that at the serum concentrations obtained in this particular study, venlafaxine XR treatment can produce a greater degree of NET inhibition. At a serum concentration of $100 \mathrm{ng} / \mathrm{ml}$, paroxetine produces an expected (see curve) $22 \%$ NET inhibition (ie, $78 \%$ of baseline). This serum concentration is well within the serum concentrations observed in this study (Figure 1). As shown in the lower right portion of Figure 3, venlafaxine occupies $50 \%$ of the NET at a combined venlafaxine + ODV concentration of approximately $325 \mathrm{ng} / \mathrm{ml}(-5.92 \log [\mathrm{M}])$. These concentrations appear to be readily attainable. Only a limited number of venlafaxine samples and very few paroxetine samples produced $\geqslant 80 \%$ NET inhibition.

There are no available data on how much NET inhibition would be necessary in the face of concurrent $\geqslant 80 \%$ SERT inhibition to produce added potential beneficial effect on efficacy. The only estimation of NET inhibition during highdose venlafaxine treatment showed only a partial inhibition of the NET, as assessed with measures of blood pressure in response to challenge with the false transmitter tyramine (Harvey et al, 2000). These investigators observed that neither venlafaxine ( 75 or $375 \mathrm{mg} /$ day) nor sertraline were significantly different than baseline; however, the $375 \mathrm{mg}$ dose clearly showed a trend portending partial NET inhibition. In that study, only maprotiline produced robust and clear evidence of NET inhibition. Recently, Blier and colleagues (Debonnel et al, 2006) reported similar findings in depressed subjects receiving venlafaxine. Therefore, if the clinical literature suggesting some added benefit of the NET inhibiting component of venlafaxine is correct, partial NET inhibition (in the face of ongoing $\geqslant 80 \%$ SERT inhibition) may be sufficient and both medications studied here can provide partial NET inhibition. No other SSRIs are predicted to possess NET inhibition at any reasonable dose. The reader should note that these studies utilizing the tyramine pressor test are a peripheral measure of putative NET inhibition on sympathetic nerve terminals. It remains 
to be definitively established whether this accurately reflects CNS NET inhibition.

In this study both paroxetine $\mathrm{CR}$ and venlafaxine XR were efficacious and generally well tolerated. The mean change from baseline in MADRS total score at endpoint was approximately 17 points in both treatment groups, which represents a substantial degree of symptom reduction. To put this level of MADRS change in clinical perspective using other efficacy endpoints, the mean proportion of patients considered to be either much improved or very much improved at endpoint based on the CGI was approximately $70 \%$ for paroxetine and $80 \%$ for venlafaxine. Furthermore, the proportion of patients considered to be in remission (ie, essentially symptom free) at endpoint, based on achieving a MADRS total score $\leqslant 10$, was $46 \%$ for paroxetine and $63 \%$ for venlafaxine, again reflective of a substantial treatment response; however, without a placebo control group, these efficacy data must be interpreted cautiously. None of the differences between paroxetine and venlafaxine on any of the efficacy parameters were statistically significant; however, again this study was not appropriately designed or powered to definitively compare the efficacy of these two agents.

Although not a primary design of the study, no differences were observed between the magnitude of NET inhibition and patient response in subjects who completed the study; however, it was of interest that all five of the paroxetine-treated subjects who had $>60 \%$ NET inhibition attained remission (Figure 4). The value of this observation is unclear as it was not fully replicated in the venlafaxinetreated subjects.

As noted earlier, whether it be synaptic and extrasynaptic concentrations of serotonin or norepinephrine or clinical response, there must be a relationship between occupancy and biological response. A lack of overt differences between SERT and/or NET occupancy and clinical response in these data should not dissuade the reader from agreeing with this hypothesis. We believe that with the tools currently available, response cannot be correlated to occupancy in the relatively narrow range of occupancies typically observed at therapeutic dosages (ie, $70-90 \%$ ). We are unaware of detailed studies of the SERT or NET that clearly show the direct relationship between occupancy and changes in available transmitter. This relationship should exist as a classic occupancy-response curve, but it may take a considerable amount of occupancy before monoamine concentrations are altered (ie, monoamine concentrations do not begin to rise until significant occupancy has occurred). Assuming that it is indeed alterations in synaptic monoamines that are responsible for initiating the clinical response process, the myriad of potential downstream processes that ultimately lead to clinical response may further dilute the ability to clearly correlate SERT or NET occupancy with treatment response.

Previous in vitro binding data and in vivo animal and human studies suggested to us that paroxetine and venlafaxine can produce both SERT and NET inhibition to varying degrees at clinically utilized doses. The present data confirm and extend these findings and provide additional impetus for further research into accurate assessment of the magnitude of combined SERT and NET inhibition and its relationship to treatment response.
In the continued absence of direct measures of NET occupancy in vivo in depressed patients (eg, use of ligands in PET or single photon emission computed tomography), this novel ex vivo uptake assay may accurately estimate CNS transporter occupancy. Our results support previous in vitro and in vivo studies that suggest paroxetine, a potent SSRI, inhibits the NET and is a dual uptake inhibitor at high therapeutic serum concentrations. The magnitude of NET blockade does not appear to match that possible with venlafaxine within the doses studied. Thus, classification of drugs based exclusively on their binding profile in vitro needs to be interpreted with knowledge about what concentrations are ultimately available at the target site. Finally, whether added NET inhibition, and of what magnitude, to SSRIs results in increased efficacy or decreased latency to efficacy remains to be conclusively determined.

\section{ACKNOWLEDGEMENTS}

We thank Drs Raj Rajani, Murray Rosenthal, and Nicholas Vatakis for their contribution to this study. We also acknowledge Peter Gething, B.S. at INC Research and Mary Kelley, Ph.D (Departments of Psychiatry and Behavioral Sciences and Biostatistics, Emory University) for performing the statistical analyses and Kathy Sheehan, Ph.D. (Department of Psychiatry, University of South Florida) for the post hoc MADRS response and remission analyses. This work was supported by a collaborative research grant to MJO from GlaxoSmithKline. The authors are also supported by NIH MH-77083, MH-69056, MH-58922, MH42088, MH-39415, and MH-68036.

\section{DISCLOSURE/CONFLICT OF INTEREST}

Dr Owens: In the past 3 years, Dr Owens has had research grants from Eli Lilly, Pfizer, GlaxoSmithKline, Merck, Lundbeck, Cyberonics, and Johnson \& Johnson. He has consulted to Pfizer, Lundbeck, Sepracor, Johnson \& Johnson, Sanofi-Aventis, Forest Labs and received speaker's honoraria from GlaxoSmithKline. Dr Owens has a patent entitled 'A method to estimate transporter occupancy'.

$\mathrm{Mr}$ Krulewicz and Dr Carpenter are employees of GlaxoSmithKline and own company stock.

Jeffrey S Simon, M.D. is a member of the GlaxoSmithKline and Wyeth Pharmaceuticals Speaker Bureaus. He has had clinical trial grant support from GlaxoSmithKline, Wyeth Research, Pfizer Pharmaceutical, Bristol Meyer Squibb, AstraZeneca, Eli Lilly, Cephalon, Sanofi, Organon, Sandoz, Merck, Upjohn Pharmacia, Otsuka, Synthelabo, and Forest Laboratories. Dr Simon has also served on advisory boards to Pfizer, Bristol Myers Squibb, Wyeth, Cephalon, Abbott and Tap Pharmaceuticals.

David V. Sheehan has had research support from Abbott Laboratories, American Medical Association, Anclote Foundation, Astra-Zeneca, Bristol-MyersSquibb, Cephalon, Eisai America, Inc., Eli Lilly \& Company, Forest Laboratories, GlaxoSmithKline, International Clinical Research (ICR), Janssen Pharmaceutica, Jazz Pharmaceuticals, Kali Duphar Laboratories Inc., Medicinova, Merck, NIH, Novartis Pharmaceuticals Corp., Pfizer, Quintiles, SanofiAventis, Tampa General Hospital, TAP Pharmaceuticals, Worldwide Clinical Trials, and Wyeth-Ayerst Pharmaceutical 
Co. Dr Sheehan is a stock shareholder in Layton Bioscience and Medical Outcome Systems. Dr Sheehan received speakers honoraria from Abbott Laboratories, AstraZeneca, Boots Pharmaceuticals, Bristol-MyersSquibb, Charter Hospitals, Dista Products Company, Eli Lilly \& Co., Excerpta Medica Asia, GlaxoSmithKline, Hospital Corporation of America, Human, ICI, Janssen Pharmaceutica, Kali-Duphar, Merck, Organon, Novo Nordisk, Pfizer Inc., Solvay Pharmaceuticals, TAP Pharmaceuticals TGH-University Psychiatry Center, and Wyeth-Ayerst Laboratories. In the past 3 years, Dr Sheehan has served as a consultant to Solvay Pharmaceuticals, Avera Pharmaceuticals, MediciNova, Jazz Pharmaceuticals, Roche, Cephalon, GlaxoSmithKline, Sanofi-Synthelabo Research, AstraZeneca, Forest Laboratories, Pierre Fabre, Alza Pharmaceuticals, Bristol-MyersSquibb, Pfizer, National Anxiety foundation, Zars Pharma, Eisai, and Applied Health Outcomes/xCENDA.

Michael E Thase, M.D. serves on the Advisory Boards for AstraZeneca; Bristol-Myers Squibb Company; Cephalon Inc.; Cyberonics Inc.; Eli Lilly \& Co.; GlaxoSmithKline; Janssen Pharmaceutica; MedAvante Inc.; Neuronetics, Inc.; Novartis; Organon Inc.; Sepracor Inc.; Shire US Inc.; Supernus Pharmaceuticals; Wyeth Pharmaceuticals, and is a member of the Speakers Bureaus for AstraZeneca; Bristol-Myers Squibb Company; Cyberonics Inc.; Eli Lilly \& Co.; GlaxoSmithKline; Organon Inc.; Sanofi Aventis; Wyeth Pharmaceuticals. Dr Thase currently has equity holdings in MedAvante Inc., and receives royalty income from the American Psychiatric Publishing Inc., Guilford Publications, and Herald House. Dr Thase has no clinical trial grant support from the pharmaceutical industry.

Dr Nemeroff: In the past 3 years, Dr Nemeroff consulted to, served on the Speakers' Bureau and/or Board of Directors, has been a grant recipient, and/or owned equity in one or more of the following: Abbott Laboratories, Acadia Pharmaceuticals, American Foundation for Suicide Prevention (AFSP), American Psychiatric Institute for Research and Educations (APIRE), AstraZeneca, BMC-JR LLC, Bristol-Myers-Squibb, CeNeRx, Corcept, Cypress Biosciences, Cyberonics, Eli Lilly \& Co., Entrepreneur's Fund, Forest Laboratories, George West Mental Health Foundation, GlaxoSmithKline, i3 DLN, Janssen Pharmaceutica, Lundbeck, National Alliance for Research on Schizophrenia and Depression (NARSAD), Neuronetics, NIMH, NFMH, NovaDel Pharma, Otsuka, Pfizer Pharmaceuticals, Quintiles, Reevax, UCB Pharma, and Wyeth-Ayerst.

Currently, Dr Nemeroff serves on the Scientific Advisory Board for Astra-Zeneca, Johnson\& Johnson, Forest Laboratories, Quintiles, PharmaNeuroBoost and NARSAD. He is a grant recipient from NIH, NARSAD, and AFSP. He serves on the Board of Directors of AFSP, APIRE, NovaDel Pharmaceuticals, and the George West Mental Health Foundation. He owns equity in $\mathrm{CeNeRx}$ and Reevax. He owns stock or stock options in Corcept and NovaDel. Patents: 'A method to estimate transporter occupancy'; 'transdermal delivery of lithium'.

\section{REFERENCES}

American Psychiatric Association (1994). Diagnostic and Statistical Manual of Mental Disorders, 4 th edn. American Psychiatric Press: Washington, DC.
Ballus CG, Quiros G, de Flores T, de la Torre J, Palao D, Rojo L et al (2000). The efficacy and tolerability of venlafaxine and paroxetine in outpatients with depressive disorder or dysthymia. Int Clin Psychopharmacol 15: 43-48.

Beique J-C, Lavoie N, de Montigny C, Debonnel G (1998). Affinities of venlafaxine and various reuptake inhibitors for the serotonin and norepinephrine transporters. Eur J Pharmacol 349: 129-132.

Davidson J, Watkins L, Owens MJ, Krulewicz S, Connor K, Carpenter D et al (2005). Effects of paroxetine and venlafaxine$\mathrm{XR}$ on heart rate variability in depression. J Clin Psychopharmacol 25: 480-484.

Debonnel G, Saint-André E, Hébert C, de Montigny C, Lavoie N, Blier P (2006). Differential physiological effects of a low dose and high doses of venlafaxine in major depression. Int J Neuropsychopharmacol 10: 51-61.

Forsman A, Ohman R (1997). Studies on serum protein binding of haloperidol. Curr Ther Res Clin Exp 21: 245-255.

Franchini L, Gasperini M, Perez J, Smeraldi E, Zanardi R (1998). Dose-response efficacy of paroxetine in preventing depressive recurrences: a randomized, double-blind study. J Clin Psychiatry 59: $229-232$.

Frazer A (2001). Serotonergic and noradrenergic reuptake inhibitors: Prediction of clinical effects from in vitro potencies. J Clin Psychiat 62: 16-23.

Gilmor M, Owens MJ, Nemeroff CB (2002). Inhibition of the norepinephrine transporter in depressed patients treated with paroxetine. Am J Psychiatry 159: 1702-1710.

Gjedde A, Gee AD, Smith DF (2000). Basic CNS drug transport and binding kinetics in vivo. In: Begley DJ, Bradbury MW, Kreuter J (eds). Blood-Brain Barrier and Drug Delivery to the CNS. Marcel Dekker Inc.: New York. pp 225-242.

Guy W (1976). Assessment Manual for Psychopharmacology, rev. edn. DHEW Pub. No. (ADM)76-338. National Institutes of Mental Health: Rockville, MD.

Hanin I, Koslow SH, Kocsis JH, Bowden CL, Brunswick D, Frazer A et al (1985). Cerebrospinal fluid levels of amitriptyline, imipramine and desmethylimipramine. J Affect Disord 9: 69-78.

Harvey AT, Rudolph RL, Preskorn SH (2000). Evidence of the dual mechanisms of action of venlafaxine. Arch Gen Psychiatry 57: 503-509.

Kenakin T (1997). Pharmacological Analysis of Drug-Receptor Interaction. Lippincott-Raven Publishers: New York.

Lieberman JA, Greenhouse J, Hamer RM, Krishnan KRR, Nemeroff CB, Sheehan DV et al (2005). Comparing the effects of antidepressants: consensus guidelines for evaluating quantitative reviews of antidepressant efficacy. Neuropsychopharmacology 30: 445-460.

Linkowski P, Hubain P, von Frenckell R, Mendlewicz J (1984). Haloperidol serum levels and clinical response in paranoid schizophrenics. Eur Arch Psychiatry Neurol Sci 234: 231-236.

Lundmark J, Walinder J, Alling C, Manniche PM, Dalgaard L (1994). The effect of paroxetine on cerebrospinal fluid concentrations of neurotransmitter metabolites in depressed patients. Eur Neuropsychopharmacol 4: 1-6.

Mahar-Doan KM, Humphreys JE, Webster LO, Wring SA, Shampine LJ, Serabjit-Singh CJ et al (2002). Passive permeability and P-glycoprotein-mediated efflux differentiate central nervous system (CNS) and non-CNS marketed drugs. J Pharmacol Exp Ther 303: 1029-1037.

Martensson B, Nyberg S, Toresson G, Brodin E, Bertilsson L (1989). Fluoxetine treatment of depression. Acta Psychiatrica Scand 79: 586-596.

Meyer JH, Wilson AA, Ginovart N, Goulding V, Hussey D, Hood K et al (2001). Occupancy of serotonin transporters by paroxetine and citalopram during treatment of depression: a [11C]DASB PET imaging study. Am J Psychiatry 158: 1843-1849.

Meyer JH, Wilson AA, Sagrati S, Hussey D, Carella A, Potter WZ et al (2004). Serotonin transporter occupancy of five selective serotonin 
reuptake inhibitors at different doses: an $\left[{ }^{11} \mathrm{C}\right] \mathrm{DASB}$ positron emission tomography study. Am J Psychiatry 161: 826-835.

Montgomery SA, Asberg M (1979). A new depression scale designed to be sensitive to change. Br J Psychiatry 134: 382-389.

Muscettola G, Goodwin FG, Potter WZ, Claeys MM, Markey SP (1978). Imipramine and desipramine in serum and spinal fluid: relationship to clinical response and serotonin metabolism. Arch Gen Psychiat 35: 621-625.

Nelson JC (1998). Synergistic benefits of serotonin and noradrenaline reuptake inhibition. Depress Anxiety 7(suppl 1): 5-6.

Nelson JC, Mazure CM, Bowers Jr MB, Jatlow PI (1991). A preliminary, open study of the combination of fluoxetine and desipramine for rapid treatment of major depression. Arch Gen Psychiatry 48: 303-307.

Nelson JC, Mazure CM, Jatlow PI, Bowers MB, Price LH (2004). Combining norepinephrine and serotonin reuptake inhibition mechanisms for treatment of depression: a double-blind, randomized study. Biol Psychiatry 55: 296-300.

Nemeroff CB (2006). The burden of severe depression: a review of diagnostic challenges and treatment alternatives. J Psychiat Res 41: 189-206.

Nemeroff CB, Owens MJ (2002). Treatment of mood disorders. Nature Neurosci 5(suppl): 1068-1070.

Nemeroff CB, Entsuah R, Benattia I, Demitrack M, Sloan DM, Thase ME (2008). Comprehensive analysis of remission (COMPARE) with venlafaxine versus SSRIs. Biol Psychiatry 63: 424-434; http://dx.doi.org/10.1016/j.biopsych.2007.06.027.

Nemeroff CB, Schatzberg AF (2006). Pharmacological treatments for unipolar depression. In: Nathan PE, Gorman JM. (eds). A Guide to Treatments that Work, 3rd edn. Oxford University Press, pp 271-287.

Owens MJ (2004). Selectivity of antidepressants: from the monoamine hypothesis of depression to the SSRI revolution and beyond. J Clin Psychiat 65(S4): 5-10.

Owens MJ, Knight DL, Nemeroff CB (2000). Paroxetine binding to the rat norepinephrine transporter in vivo. Biol Psychiatry 47: $842-845$.
Owens MJ, Knight DL, Nemeroff CB (2001). Second generation SSRIs: human monoamine transporter binding profile of S-citalopram and R-fluoxetine. Biol Psychiatry 50: 345-350.

Owens MJ, Morgan WN, Plott SJ, Nemeroff CB (1997). Neurotransmitter receptor and transporter binding profile of antidepressants and their metabolites. J Pharmacol Exp Ther 283: 1305-1322.

Poirier M-F, Boyer P (1999). Venlafaxine and paroxetine in treatment-resistant depression. Br J Psychiatry 175: 12-16.

Potter WZ, Scheinin M, Golden RN, Rudorfer MV, Wowdry RW, Calil HM et al (1985). Selective antidepressants and cerebrospinal fluid: lack of specificity on norepinephrine and serotonin metabolites. Arch Gen Psychiat 42: 1171-1177.

Rochat B, Baumann P, Audus KL (1999). Transport mechanisms for the antidepressant citalopram in brain microvessel endothelium. Brain Res 831: 229-236.

Seth R, Jennings AL, Bindman J, Phillips J, Bergmann K (1992). Combination treatment with noradrenalin and serotonin reuptake inhibitors in resistant depression. Br J Psychiatry 161: 562-565.

Sheehan DV, Lecrubier Y, Harnett-Sheehan K, Amorim P, Janavs J, Weiller E et al (1998). The Mini International Neuropsychiatric Interview (M. I. N. I.): the development and validation of a structured diagnostic psychiatric interview. J Clin Psychiatry 59(suppl 20): 22-33.

Tatsumi M, Groshan K, Blakely RD, Richelson E (1997). Pharmacological profile of antidepressants and related compounds at human monoamine transporters. Eur J Pharmacol 340(2-3): 249-258.

Thase ME, Entsuah AR, Rudolph RL (2001). Remission rates during treatment with venlafaxine or selective serotonin reuptake inhibitors. Br J Psychiatry 178: 234-241.

Tyrer P, Marsden CA, Casey P, Seivewright N (1987). Clinical efficacy of paroxetine in resistant depression. J Psychopharmacol 1: 251-257.

Weiss J, Dorman S-MG, Martin-Facklam M, Kerpen CJ, KetabiKiyanvash N, Haefeli WE (2003). Inhibition of P-glycoprotein by newer antidepressants. J Pharmacol Exp Ther 305: 197-204. 